\title{
The Experience of Receiving a Kidney Transplant from a Deceased Donor: Implications for Renal Services
}

\begin{abstract}
Objective: The study aimed to explore the psychological experiences of receiving a kidney transplant from a deceased donor and to examine resulting implications for renal services.
\end{abstract}

Design: A qualitative design was utilised within an interpretative phenomenological analysis (IPA) framework.

Main Outcome Measures: Semi-structured interviews were conducted with six adults (male $=5$, mean age $=45$ years) on their experiences of receiving a kidney transplant from a deceased donor. All participants had their transplant within the preceding 21 months. Data was analysed using IPA.

Results: The four elicited themes incorporate recipients' positive feelings about receiving a transplant, mainly arising from the new-found freedom that this entails, in addition to strong feelings of gratitude towards their donors. They also capture challenges, such as the uncertainty of living with a transplanted kidney, and highlight the increased dependence on others throughout the transplant process.

Conclusion: The findings indicate a range of psychological, social and occupational experiences for participants. It is concluded that optimal care in renal services would incorporate a holistic approach to pre and post-transplant care; identifying and supporting the needs of transplant recipients. A biopsychosocial model of care may enhance service user well-being. Potential areas of future research are explored. 
Key Words: Kidney Transplantation; Qualitative Research; Interpretative Phenomenological Analysis; Service User Experiences; Renal Services; Biopsychosocial Model.

Disclosure Statement: The authors report no conflict of interest.

\section{Introduction}

End-stage renal disease (ESRD) follows a gradual decline in kidney functioning, often due to chronic medical conditions such as diabetes or hypertension. It is currently treated either by renal transplantation or dialysis (Christensen \& Ehlers, 2002). Renal transplantation is generally the preferred treatment as it tends to prolong life-span and lead to an improved quality of life, in addition to being more cost-effective than dialysis (Gordon, 2001). Switching from having dialysis to receiving a kidney transplant can have a positive impact on the emotional well-being of individuals with ESRD. This is mainly due to the significant constraints caused by dialysis (e.g. reduced independence), many of which can be resolved by transplantation (Wainwright, Fallon, \& Gould, 1999).

Despite the proposed benefits of transplantation, quantitative studies have found depression and anxiety to be prevalent in kidney transplant recipients (e.g. Cukor, Rosenthal, Jindal, Brown, \& Kimmel, 2009; Karaminia et al., 2007; Noohi et al., 2007). In research that has found no significant differences in levels of anxiety and depression between transplant recipients and controls, other psychological difficulties, such as fear and anger, are evident (Pascazio et al., 2010). However, Kuntz and Bonfliglio (2011) found that the percentage of participants presenting with depression and anxiety symptoms were lower than expected when compared to percentages from previous studies. 
Complementing the above literature, a small body of qualitative research has helped to develop an understanding of the needs and hopes of kidney transplant recipients. For example, Luk (2004) details how receiving a kidney transplant can enhance physical and social functioning, and outlines participants' needs for obtaining more information about medical side-effects, exercise and diet. It has also been found, through the use of focus groups, that having a kidney transplant can lead to long-term psychosocial effects, such as ongoing gratitude to the donor, experiencing medication as intrusive and feeling different to others (Orr, Willis, Holmes, Britton, \& Orr, 2007). Furthermore, in a phenomenological study examining participants' experiences directly after transplantation and before discharge from hospital participants detailed how they coped with the transplant and their desire for support systems to assist them in this process (Wiederhold, Langer, \& Landenberger, 2011).

Receiving a kidney from a donor presents additional challenges. For example, concern for the health of the donor can be a central experience for living transplant recipients, whilst recipients of a kidney transplant from a deceased donor are more likely to believe they have taken on characteristics of the donor (Sanner, 2003; Schlebusch, Pillay, \& Louw, 1989). Furthermore, the experiences of those who have received a kidney transplant from a deceased donor can be impacted by the failure to acquire the organ from a living donor (Sanner, Lagging, \& Tibell, 2011) and by the sudden nature of the surgery that is a necessary part of receiving deceased organs (Sanner, 2003). Recent interpretative phenomenological analysis (IPA) studies have added further to this knowledge base. Spiers and Smith (2015) outline the experiences of individuals who are waiting for a kidney from a deceased donor. These experiences include managing the uncertainty of this wait and considering a variety of complex cognitions relating to the donor such as coming to terms with the fact that somebody must die in order to become a donor. An IPA study by Spiers, Smith and Drage (2015) focuses on the lived experiences of participants who have received a kidney from a living 
donor. This paper highlights the complex nature of their relationship with the donor which can be a changeable process for recipients over time. For example, some participants moved from a degree of emotional confusion due to an apparent sense of obligation to feel gratitude towards the donor to a more genuine love and respect for the donor.

Taking this disparity between receiving a kidney from the two different types of donor into consideration the aim of the present study was to learn more about potential psychological experiences that can arise specifically for recipients of a kidney transplant from a deceased donor and to identify implications for renal services. In order to achieve this, a qualitative approach was adopted to elicit and analyse adults' experiences of receiving a kidney transplant from a deceased donor.

\section{Method}

\section{Design}

Data was collected via semi-structured interviews and was analysed with Interpretative Phenomenological Analysis (IPA) (Smith, Flowers, \& Larkin, 2009). IPA studies seek to identify what the experiences and meanings of a phenomenon are like for a well-defined sample. The approach highlights the importance of individual and personal perceptions, as well as shared experiences, and aims to achieve an "insider's view" of the research topic. All participants were recruited via a renal service within the National Health Service (NHS) in the UK, a publicly funded health service that provides free health care to UK citizens. This service provides pre-transplant care in addition to long-term posttransplant care. The study was approved by a UK National Health Service (NHS) Research Ethics Committee. 


\section{Sampling and Participants}

The intense analysis of individual accounts and the examination of shared meaning, along with any nuances in these meanings, are reflective of the idiographic characteristic of IPA which is generally characterised by small and homogeneous samples (Smith \& Osborn, 2008). As such, purposive sampling methods were used to gain a homogenous sample of participants.

Inclusion criteria were as follows: aged 18 years or over, stable blood results, fluent in English, receiving post-transplant care in the service, and had received a kidney transplant from a deceased donor no longer than 24 months previously.

Thirty-one potential participants were identified from the patient register by a transplant nurse practitioner employed by the recruiting service. They were invited to contact the researcher directly if interested in participating and six people agreed to take part. The mean age of participants was 45 years and all participants were white British. Each participant was receiving post-transplant care and had received dialysis prior to transplantation. Further demographic details are included in Table 1.

[Insert Table 1 about here]

\section{Data collection}

Two participants were interviewed in an office within the recruiting service and four participants were interviewed in their homes. A topic guide was prepared following a review of the literature and discussions within the research team. This included questions relating to general perceptions of having a kidney transplant and the impact this had on the life of the 
participant (e.g., 'How did you feel during the build-up to the transplant?', 'How has having a kidney transplant affected your life?', 'What does having a kidney transplant mean to you?'). The interviews were audio-recorded (mean duration 60 minutes) and transcribed verbatim.

\section{Analysis}

The interviews were transcribed and analysed by the first author and audited by the second author in accordance with established guidelines for IPA techniques outlined by Smith et al. (2009). Analysis focused on identifying what participants' experiences were and how they made sense of them. This process included identifying and suspending any assumptions about the topic under investigation.

To begin with, each transcript was read in order to identify themes from a psychological perspective and with a focus on the phenomena being researched (how adults experience kidney transplantation from a deceased donor). The left-hand margin of the transcript was used to note down any initial impressions on parts of the text of relevance to the central research question. Following this, the right-hand margin was then used to record the fundamental substance of the text, in the form of key words and phrases which captured what it was like for participants. Once this process was completed for each transcript a list of the emergent themes was collated so that commonalities and nuances within and between participants' data could be examined. Patterns across participants were then explored, including any areas of convergence and divergence across participants' data.

Next, related themes were put together and the final theme titling modified to reflect the depth and breadth within and across accounts. This stage of analysis focussed on producing a parsimonious account of the study data which resulted in a four-theme narrative structure encompassing the totality of the data contained in the larger set of themes. 


\section{Findings}

Analysis identified four themes: discovering a new life; experiencing support from others; experiencing challenges post-transplant; and remembering the donor and the donor's family. Each theme is presented below. In instances where verbatim quotes are utilised a short pause is illustrated by..., a long pause is conveyed by [pause], and [...] indicates that a non-essential part of text has been removed.

\section{Discovering a New Life}

Participants described enjoying and looking forward to a new life following the kidney transplant. An important part of making sense of this new life was directly related to not having to undergo dialysis anymore. The two main difficulties with dialysis centred on its unpleasantness as a treatment and the major restrictions that it placed on participants' lives. Alan referred to dialysis as a 'horrendous' treatment that 'messes up your life...tremendously'. He often felt dizzy following dialysis and it sometimes led to him feeling very ill the following day:

But I would get out of bed... and I'd end up on the floor. And I'd end up crawling round. And I would shout to her, and say, 'I'm dying here. There's something wrong here. I cannot go to work this morning'.

In addition to emphasising the physical pain that he was feeling Alan's reference to 'dying' may also imply that his freedom and sense of agency was ending due to the restrictions of dialysis. John reported a similarly bleak view of dialysis, associating it with sickness and lack of motivation, 'you just sleep....and you feel sick... and you just want to go to sleep [...] it wasn't really much of a life' and Rob found planning trips away particularly difficult, 'We 
couldn't go Friday, cos I had dialysis on the Saturday [...] you had to work your weekend accordingly'.

Consequently, each participant emphasised the increasing freedom that they had in their lives post-transplant. They were essentially moving closer to what they considered to be normality. John outlined a gradual improvement where he felt himself becoming a little bit stronger every day.

But yeah, my experience after the first three days was, in my eyes, gradually getting better. Going from my bed to my chair to walking around and...I could even go to the bathroom, which I couldn't do before cos I had a catheter in.

Despite some inconveniences of having his bladder function restored he particularly appreciated this, 'Now I know what everyone feels like getting up during the night and having to go to the toilet [laughs]'. Mary described being able to attend events that she could not attend in the past and feeling a hope for the future that was not there pre-transplant:

It definitely means I've got a future [...] I never used to think past...you know, I could never...envisage even having another holiday or...you know, even going away for a night or anything like that. It just seemed quite...um...locked in your own home really. But, it's definitely given me hope.

Participants celebrated this new life and move towards their view of normality. Alan described having 'the freedom...to...do... what you want, when you want'. Again, the posttransplant contrast to dialysis was central to this freedom:

I'm driving about thinking, 'Oh. I should be on dialysis now. Them poor buggers in there... are...are on dialysis. Sat on a bed with two needles in them. For six hours they're in there... and I don't have to do that. I just do not have to do that'. You 
know...I can't stress it enough really. I can't put it into words too much. You've read about it. Everybody says it, and it is...it's just freedom...you know.

Receiving a transplant had a similar impact on Matthew:

going away to me daughter's...um...graduation ceremony. When I went last year to help her...um...again...the sort of logistics surrounding the dialysis came in. I had to sort of plan via...um...how to live my life via the...the bags needed changing, I had to take a box of stuff with me to $\mathbf{X X X X X X X}$...you know, I did the dialysis in the bathroom, et cetera, you know. Just freedom really, it's freedom from...the shackles have been sort of lifted really, you can almost get back on with your life and you're able to do things.

Alan described enjoying a number of new roles following the transplant such as doing school runs and going to DIY shops:

I take the younger one to school $[\ldots]$ me son's at university at the minute $[\ldots]$ I was running him to school, running him to football [...] I go to all these places, buy all me screws and nails... and I do all these jobs [...] I couldn't do any of that on dialysis [...] you're not fit enough [...] But, um...no, it's good.

The transplant process helped David to look at life differently, 'It makes you appreciate life a lot more...it sort of like changes the whole way that you look at life'. For Rob, simply reflecting on the fact that he had been given a new kidney was sufficient to fill him with happiness and gratitude, 'Only delight. Happiness. Gratitude. Simple as that, you know'.

As has been illustrated above, the participants engaged in highly charged use of linguistics to emphasise their new life and to describe their perceived misery attached to the old life of dialysis. Dialysis was like a prison in which 'shackles' were used to constrict and 
restrain resulting in participants being 'locked' at home. This sense of entrapment was likened to death and 'dying', not just regarding the fear of physical death but also the death of a way of life. Transplantation returned this way of life and brought 'freedom', 'delight' and 'gratitude'. Perhaps freedom from the shackles of having to undergo dialysis and also from the consequent restrictions of dialysis on participants' lives preventing them from leading the life they desired.

\section{Experiencing Support From Others}

The role of support from others during the transplant process was an integral part in promoting participants' psychological wellbeing. Alan referred to his partner and other partners as 'unsung heroes' due to their help and support:

And she'll help me out of the car...because I can't walk so well if I've had dialysis....and when I had my kidney transplant...well, I had to be helped out of the car and things like that, cos you can't bend so well. Um... and they...they'll tidy the house, and do the shopping. And I just have to sit there.

Rob emphasised how his friends were overjoyed for him when he received the transplant, 'My friends...over the moon for me.' John's parents visited him every day in hospital and his girlfriend attended every hospital appointment with him, while his friends used humour to support him, 'It meant everything to me. I don't think I would have got through like I did without family and friends'. Mary described a defined support network with her in the centre that included her immediate and extended family:

We've become quite a close family unit really...just, like with me in the centre for the time being and...you know, everybody else supporting, you know, like a tiered 
support network really. I have definitely been supported a lot by...by my mum...and my dad. And my sister as well, and the extended family as well.

Participants identified other patients as an important support from the dialysis stage up to soon after their kidney transplant. This support was valued, although in some cases they experienced feelings of loss when the support was no longer present. David spoke about making contacts with other transplant recipients through forums and websites, and he identified their ability to understand what he has been going through as a significant support:

... you don't ever feel like you're on your own. You can talk to anybody with the touch of a button...anyone you feel you need to. Um...so, yeah...it just helps you...just to have their number is enough sometimes...to put your head straight... and make you think, "Okay, there's somebody else out there" [...] there's someone out there who knows what I'm going through. You know, someone out there...who's been through similar things that I have. That's always important.

Matthew valued how other patients on the ward supported him on the day of the surgery:

I don't think I realised in my own mind the gravity of what was... what was coming...we just really had quite a laugh that day with people on the wards. There was people I gelled with and...it was...it was actually quite a good day, really.

Rob had a similar experience before and after the transplant. Even though he was delighted to finish dialysis, he missed the rapport that he enjoyed with fellow patients, 'I miss the friends I've met, you know. Whereas you used to see 'em...like, three times a week... all of a sudden, they're not there'.

Mary found that staff members were particularly good at supporting her during times of stress, 'Well they're very good at, you know...coping...like reassuring me and...it is nice 
to know that they are there'. Others had similar experiences; Rob experienced staff as caring and efficient, 'The doctor...he explains everything [...] He's a very caring gentleman $[\ldots]$ the nurses... as far as they can be... are very good...very hospitable...you can't fault them'. Matthew found the light-hearted attitude of staff to be very helpful to him in getting through a potentially traumatic experience. Just before the operation, they supported him to feel relaxed and calm by talking about a sporting event:

I found I was in conversation with...even the surgeon, the anaesthetist et cetera...about this boxing match. It was quite funny, and everything was so matterof-fact, in all honesty. It was a great way to actually approach an operation. I felt the people that did it there...they just...it was just right and the surgeon said, 'Right, I've got a kidney to prepare'.

However, there were also some divergences among participants regarding their experiences of support from staff. Most of the participants had only positive experiences of staff at the service but Mary and Matthew had some difficulty with the support they were receiving. Although the staff may have been trying to protect Mary when she was considering a donor she simultaneously felt dismissed by them:

the only complaint I would ever really have is when I first came $[\ldots]$ I think I found it that I was in a bit of a shell-shock situation, and I think the kind of response I got was very much...it was very much a jovial thing...um...now I don't know whether it was just them trying to keep my spirits up or something like that.

Furthermore, Matthew particularly enjoyed the interactions that he had with some of the nursing staff but he found others more informal and he struggled with this: 'Um [pause] not as chatty really, to be quite honest. Not as interested...I suppose it's wrong to say, "Not 
as interested". Obviously they've got the patient's welfare at heart [...] Some, I suppose, are friendlier than others.'

\section{Experiencing Challenges Post-Transplants}

Despite the positive changes to their lives, participants experienced uncertainty following surgery, 'At the start it wasn't too good cos the kidney wasn't taking...it wasn't...doing what it was supposed to do' (John). Due to the lowering of their immune systems as a result of taking immuno-suppressants increased susceptibility to cancer was a worry for some, 'So, I'm a hundred times more likely to get this cancer...and I'm two hundred and fifty times more likely to get that cancer. So, that is worrying...' (Alan). Alan's use of numbers to emphasise his point indicates a significantly heightened sense of threat of illness and highlights the degree of anxiety he is feeling. This anxiety was also felt by Rob who worried about getting an illness that was particularly dangerous to a kidney transplant:

it was... a strain of pneumonia. I couldn't tell you the name of it, like, you know. But, um...it were supposed to be one of the worst ones for kidney transplants. Which I were worried...cos me kidneys started fluctuating a bit, like, you know... while I had this.

An uncertainty about the future was evident for all participants. This was primarily based on the knowledge that their new kidney would eventually fail and they would need to return to dialysis treatment, 'I would hate to go back on dialysis... absolutely hate it. I think I will get very depressed if I go back on dialysis (Alan)'. John, however, was concerned about his future full-time employment opportunities following his transplant, 'I'm worried about a full-time job as well. Lifting heavy stuff. It's like, when can I start doing that. I don't know when I can start doing stuff like that'.. 
Some of the participants found that others lacked an understanding of the difficulties they faced following their kidney transplant. David had a sense that people believed that 'he doesn't have to struggle anymore' post-transplant, adding that 'it doesn't necessarily work that way'. Mary had a similar experience despite feeling that she was 'just being held together by all of these drugs'. The image of 'just being held together' may symbolise a deep vulnerability that exemplifies immense struggle as this fragile support framework apparently could break at any time. There is a sense of isolation attached to this as it is a battle that is invisible to others who can therefore offer no support. The lack of certainty attached to this is similar to Rob's 'fluctuating' kidneys which implies that his kidneys could either stop working altogether or else open the door to severe illness at any time.

Lack of understanding was particularly stressful for Mary and Matthew in their work environment:

You do your work...you work til half past five every night. And...I suppose...you're being treated as normal and you're being taken for granted, as such. And then the sort of thought about, 'You've had a major operation' just seems to sort of...go....and get forgotten almost (Matthew).

Mary described trying to educate staff at work about her condition, but this had no impact and caused her considerable stress to the point that it prevented her from focusing on herself and her health:

I seem to have...um....a lot of problems at work [...] a lot just seems to be on me trying to be treated fairly at work rather than...me, looking after me. You know, I seemed to be fighting right up to when I went off. 
The use of language highlights the extent of the challenge these participants faced. They initially had to fight to survive a 'major operation' but the battle merely switched from surviving the transplantation process to 'fighting' the pressures that society is placing on them. Although Alan was retired at the time of the interview he also reflected on his experience of work. His experience differed from that of Matthew and Mary in that he found his employers supportive but he appeared to place a self-imposed pressure on himself as a result of missing work for appointments, 'so they were good [...] they don't just...um...discard you sort of thing. But no firm likes somebody going off three afternoons a week.' The use of the word 'discard' is powerful in this context. Although his employers did not discard him there is an impression here that he possibly feared that this would happen and again a high sense of vulnerability is evident. The other participants did not refer to a lack of understanding in the work-place, which could be explained by their differing circumstances. Rob was retired, David was unemployed and John was working part-time.

Lack of understanding was not limited to the workplace, however. Alan attributed lack of understanding in people to an absence of experiencing illness themselves, 'All these people who just walk about without any problems...they don't appreciate what it's like...when you're ill'. Matthew found that while his friends were sympathetic towards him initially post-transplant, it was soon after assumed that he was back to full health, 'I think you're almost seen as sort of normal...you're never truly normal...you get tired a bit more, maybe, than you would do before'.

There were a number of other challenges that participants faced. Alan described feeling more upset following his transplant and suspected that this was caused by his medication, 'I get upset more. I, um... whether it's the tablets...you are on a lot of tablets when you, um...have had a transplant [... I'm on about 20 a day now, say...15 to 20 a day 
now - I think they have an effect on your body.' Similarly, Matthew felt more emotional post-transplant and felt that the immuno-suppressants may have had a part in this:

I seem to have a sort of sense of heightened worry as well $[\ldots]$ again, trying to reason in me own mind...if that is the immuno-suppressants [...] I don't really know...and... at work I think I may be slightly less tolerant of people than I used to be.

David experienced a different type of challenge in that he began to feel pressure to 'succeed in life' a few months post-transplant, 'It's pressure you put on yourself...to think, "Right I have to perform now. I have to live my life. I have to get on with things. I have to get a job...do this...get a family, kids"'. He reported that he was unable to pursue these goals previously due to health problems but following the transplant this personal challenge was experienced as a significant pressure.

\section{Remembering the Donor and the Donor's Family}

Each of the participants remembered the donor in some way and expressed gratitude towards them. They each possessed small bits of information about the donor but the age of the donor was particularly significant to participants:

Well, if it's a younger guy then obviously the kidney is going to last longer and I'll look after it more. But if it's an older guy...the chances of it keeping or rejecting is a lot...I think...I think they said it's higher for rejecting. But a XXXXX year old is obviously a good age. Hopefully it's going to stay in for a few years (John).

However, receiving a kidney from a young donor resulted in mixed emotions for some participants. In addition to the hope that a younger organ increases the likelihood of a longer survival, there was the realisation that somebody young with a bright future ahead of them had died: 
I was lucky, I mean it was...it was a young lad...who was only XXXXX. They don't give you all the details but... and that...that upsets you really. You feel bad about that. And I still do. Um...it turns out that somebody has died for you to get this kidney (Alan).

Matthew similarly reflected on the sad circumstances that resulted in him receiving a kidney, 'So again you think of the donor. You think of their circumstances. They had to die...to sort of...you know, that sort of side comes across your mind from time to time'.

Writing a letter to the donor's family was very important to all participants. John, Alan, Mary and Matthew had written to the family already, although none had received a response. There was an understanding among participants that the family had lost a loved one and that writing back was not a priority for them:

So, um...writing that letter was very hard...um...to somebody who's lost their son...or their brother...or, whatever it was. I don't know what his name was, I don't know where he lived, or anything. And I don't know the circumstances, you know. It could have been a car crash...you don't know. You don't know. And that's another things that's strange. Um...anyway, I haven't heard back. But, no problem (Alan).

Matthew felt a need to write a letter 'in respect of' the family'. David and Rob had not written to the donor's family yet, but were waiting for the right time to do so. Timing appeared to be particularly relevant to some participants for different reasons. David wanted to ensure that his kidney was working well before writing to the donor's family:

Um...but I've left it 12 months [...] cos then you know the transplant's established...there's not much point in writing to them after six months...or three 
months...or less than that...cos you don't want to write to them and say, 'Well, it's great after three months and then something happens.

Some participants spent a lot of time thinking about what to write in the letter. They wanted to express their gratitude and appreciation in the right way, but this was proving to be a difficult task for some:

... and I've been thinking in all that time actually how to put across... what I felt about it...without it seeming melodramatic or...you know...trying to really say what I meant...rather than what I thought people would want me to say (Mary).

Rob experienced a similar struggle:

We...we're hoping to write a letter. Well, we've been saying this for the last...two or three months... but we can't really... work a letter out. We're trying to work it out...so...um, to show our appreciation to the donor... and the family of the donor... which has changed me life, like, you know [...] You have to put it into words on a piece of paper... and show your feelings... is very difficult...you know...to explain, like, you know. I know there's words like saying that you appreciate [...] But, um...it's not showing your actual feelings [...] you can't explain it (Rob).

Similar to Matthew's assertion that somebody had to die for 'you' rather than 'I', Rob's use of 'we' and 'you' instead of 'I' creates a certain amount of distance from the donor process. This may be utilised by participants to depersonalise the process in order to prevent them from becoming completely overwhelmed. It may also serve a purpose for participants by moving them from a place of isolation that must be negotiated alone to a more supportive place that includes others such as family members and loved ones. 
Some expressed a strong bond with the donor and the family, and believed that they had to do their very best to justify receiving the kidney. David felt that he owed the donor's family to keep the kidney healthy and to succeed in life, 'I feel like now I owe...I sort of like to have an onus...to the family...to make sure it works... and to make sure that I'm doing well...for his memory, the person who gave me the kidney'. Mary's bond with the donor was represented in many different ways. She considered organising a remembrance rose for the donor, and she thanked the donor at a party she had for the jubilee. The donor became part of the celebration and was remembered by Mary in the presence of her family:

I just said a few words about my thank you to everyone, but it was also for somebody who is not here we need to thank. And that was my donor, so, you know...I wanted to make sure that she isn't forgotten.

In this way, remembering and appreciating the donors and their families was an integral part of each participant's transplant experience.

\section{Discussion}

The present study adds depth to existing literature that examines psychological wellbeing in kidney transplant recipients (e.g. Cukor et al., 2009; Karaminia et al., 2007). It helps provide a more in-depth understanding of some of the psychological difficulties experienced, supplying detail of particular concerns. Such concerns include living a life of uncertainty due to an awareness that the organ could fail at any time, fears of contracting serious illness due to a reduced immune system, and experiencing feelings of anxiety due to adverse side-effects from medication as well as feelings of sadness as a result of the donor's death.

This study also offers some possible explanations regarding mixed evidence relating to the presence of anxiety and depression in kidney transplant recipients. Some research has 
found evidence of depression and cognitive decline in kidney transplant patients (e.g. Troen et al., 2012), while other studies have found high rates of anxiety and depression in people living with kidney transplants (e.g. Arapaslan, Soykan, Soykan, \& Kumbasar, 2004). However, as previously mentioned, Kuntz and Bonfliglio (2011) found the percentage of psychological distress among such individuals to be lower than expected and Pascazio et al. (2010) found no evidence of anxiety and depression in kidney transplant patients, identifying other psychological difficulties, such as fear and anger, instead.

The potential reasons for mixed findings are complex and multifactorial and could relate to factors such as the emotional well-being of transplant recipients at different time intervals post-transplant, and the possibility of labels such as anxiety and depression being overly simplistic due to the wide range of emotions and challenges experienced by transplant recipients. The findings in the current study suggest that conflicting emotions, such as feelings of joy and excitement and feelings of fear, anxiety and frustration, can co-exist and/or fluctuate rapidly. Feelings of hope are evident in this study as participants could look to the future without the burden of dialysis. Simultaneously, however, they are also aware that graft rejection could occur and that their difficulties have not been fully understood by others. Therefore, the mixed evidence regarding the psychological well-being of kidney transplant recipients is more understandable when one considers the complex nature of the challenges faced. Indeed, this is supported by recent qualitative literature that specifically focuses on the relationship with the donor during both the pre and post-transplant stages, highlighting the complexity and sometimes contradictory emotional impact that this relationship elicits (Spiers and Smith, 2015; Spiers, Smith and Drage, 2015).

A further important finding from this study relates to the importance of social support for kidney transplant recipients. This was identified as beneficial by participants and came from a number of sources which complements some existing literature emphasising the 
importance of marital social support in kidney transplant recipients. High levels of marital discord have been found to be correlated with high anxiety and low quality of life, as well as poor quality relationships in kidney transplant recipients (Einollahi et al., 2009). Moreover, being married pre-transplant has been found to be a protective factor for survival of the graft post-transplant (Naiman et al., 2007). This prior research points towards the relevance of social support and the present study identifies the types of support that may be most helpful to kidney transplant recipients, namely family, friends, staff and other patients.

An understanding of the findings of this study, supported by existing literature, can be enhanced when examined from the perspective of the biopsychosocial model (Engel, 1980). This model adds a psychosocial component to the traditional biomedical approach and considers physical illness from a biological, psychological and social perspective. The biological component to ESRD and kidney transplantation is clear and is the primary focus of national publications documents that relate to care for kidney transplantation (e.g. National Kidney Foundation, 2011). Although some such documents also acknowledge the need for psychological and social support (e.g. Department of Health, 2005) the findings from this study emphasise the considerable role of both of these components in the well-being of individuals who have received a kidney transplant from a deceased donor. Adjusting to life post-transplant and living with uncertainty are psychological factors that contribute to overall well-being. Likewise, the highly significant role of social support appears very relevant, as well as understanding the negative impact that unsupportive judgements and interactions from others can have. Furthermore, receiving a transplant from a deceased donor can lead to psychological distress due to the knowledge that the transplant was dependent on another individual's death. 


\section{Implications for Renal Services}

Drawing on this model, biological, psychological and social factors should each be considered during the care of recipients of a kidney transplant from a deceased donor. Psychological and social support for patients and carers is included in National Service Framework for Renal Services documents (Department of Health, 2004; Department of Health, 2005) although guidelines in these documents and in clinical guidelines published by the UK Renal Association (Baker, Jardine, \& Andrews, 2011) largely focus on the health of the new graft and related physical health issues. The outcomes from this study highlight how psychological need co-exists with physical health needs for post-transplant recipients and the potential benefits, therefore, of a holistic model of care broadening the focus on physical health to incorporate psychological, emotional and social factors also. Maintaining a medical focus on post-transplant care and, by definition, overlooking psychological and emotional responses is likely to impact on recovery and rehabilitation.

Appropriate screening of holistic (or psychosocial) needs would reduce the burden on transplant patients to raise issues that may not otherwise be considered appropriate in a medically-focused clinic. This, in turn, would provide a more effective and efficient pathway for appropriate and more meaningful support of post-transplant patients according to their individual experiences and need. Early identification of psychosocial issues beyond the scope of the transplant clinic would facilitate appropriate referrals to and more detailed assessment by renal support services such as psychology and social work. Screening tools designed to help normalise and briefly explore the potential psychological challenges and difficulties identified in this study may be particularly useful for patients. These include feelings of anxiety relating to fear of graft rejection, the emotional consequences of receiving an organ from somebody who is deceased and managing judgements and lack of understanding from others. Assessment of more general psychological well-being as well as 
transplant recipients' perceptions of professional and social support would help to inform other potential factors contributing to distress enabling further opportunities for psychological support.

A central part of a holistic framework of patient care is awareness among renal health professionals of the types of psychological, emotional and social needs that may be experienced by transplant patients. Education and training around communication and offering basic emotional support to patients may be necessary in order to support this process and create an environment in clinics where psychological distress can be expressed and, thus, identified. Therefore, although expressions of positive emotion relating to the transplant process should be welcomed, exploring and welcoming the potential presence of conflicting emotions such as anxiety and fear seems particularly important during clinics in order to ensure that psychological need is identified.

In relation to social needs, as well as the psychological and physical preparation for transplant, it may be beneficial to patients if renal services offered a broader level of support by staff and/or other patients both pre- and post-transplant. Attendance at staff-led information and support groups and hearing the experiences of transplant recipients could be a valuable way of normalising psychosocial experiences particular to renal transplantation and could help to more fully prepare patients at both pre and post-transplant stages, helping them to manage expectations. Peer support is particularly helpful for patients with chronic kidney disease for enhancing confidence and knowledge, reducing feelings of isolation and providing reassurance (Wood, 2014). Findings from this study suggest that this would continue to be the case post-transplant. 


\section{Limitations and Future Research}

The homogeneity of the sample was impacted by the amount of time which had passed since the kidney transplant, which varied over a 17 month period. Furthermore, the age of participants ranged from 26 years and 68 years. This in itself resulted in a different focus among participants; for example, some were in retirement whilst others were focusing on future employment opportunities. It is also noteworthy that five of the six participants were male although this may be somewhat reflective of recent statistics in the UK that demonstrate that $60 \%$ of transplant recipients from a deceased donor were male (NHS Blood and Transplant, 2015). However, it is important to recognise the potential impact that this may have had on findings. Although participants drew on support from a range of sources all spouses/partners involved in a supportive role were female. Different experiences may have been elicited had there been more males in a caring role. Although the experiences recounted were not provided in apparent gendered ways (for example, Mary's experiences bore a lot of comparisons with the males in the sample), it is possible that the reliance on a predominantly male sample obscured the particular gendered meaning-making that a focus on exclusively male or females samples would afford. Research examining all male and all female samples, with a focus on gender identity, would therefore be a useful extension of the present research.

Research has found that individuals can face different challenges during the first 12 months post-transplant when compared to both 24 and 36 months post-transplant (Pérez SanGregorio, Martín-Rodríguez, Galán-Rodríguez, \& Pérez-Bernal, 2005). Future qualitative research should explore specific experiences among those who have received a kidney transplant from a deceased donor during these distinct time periods.

Future research should also explore the experiences of individuals post-transplant according to proximate age-ranges. The experiences of adolescents, young adults, middle- 
aged adults and older adults should be examined separately due to differing life experiences and expectations that can exist during these times. Additionally, some challenges facing individuals in the work place post-transplant are evident in this study. Future research should specifically examine the experience of returning to employment following transplantation in order to learn more about these and other potential challenges. Finally, further studies should also separately explore the experiences of living kidney transplant recipients.

\section{Conclusion}

The purpose of this research was to elicit information about the experiences of recipients of a kidney transplant from a deceased donor in a UK renal service, with a view to learning more about the complexities and challenges that they face so that services can better meet their needs. This research suggests that these individuals experience a range of physical, psychological and social needs that would be served best using a biopsychosocial framework. This would involve actively monitoring each of these domains both within and outside of clinics and incorporating an understanding among professionals that psychological and social fragility can co-exist with stable physical health post-transplant even on occasions when positive affect is being expressed by patients. A shift towards a biopsychosocial approach should facilitate improved quality of patient care post-transplant and referral to appropriate services as required, including psychology and social work services. 


\section{References}

Arapaslan, B., Soykan, A., Soykan, C., \& Kumbasar, H. (2004). Cross-sectional assessment of psychiatric disorders in renal transplantation patients in Turkey: a preliminary study. Transplantation Proceedings, 36(5), 1419-1421. doi:10.1016/j.transproceed.2004.04.087

Baker, R., Jardine, A., \& Andrews, P. (2011). Clinical practice guidelines: Post-operative care of the kidney transplant recipient - final version. Hampshire: The Renal Association. Retrieved September 13, 2016, from http://www.renal.org/clinical/guidelinessection/Post-operative-Care-KidneyTransplant-Recipient.aspx\#downloads

Christensen, A. J., \& Ehlers, S. L. (2002). Psychological factors in end-stage renal disease: An emerging context for 26ehavioural medicine research. Journal of Consulting and Clinical Psychology, 70(3), 712-724. doi: 10.1037/0022-006x.70.3.712

Cukor, D., Rosenthal, D. S., Jindal, R. M., Brown, C. D., \& Kimmel, P. L. (2009). Depression is an important contributor to low medication adherence in hemodialyzed patients and transplant recipients. Kidney International, 75(11), 1223-1229. doi: $10.1038 / \mathrm{ki} .2009 .51$

Department of Health. (2004). The national service framework for renal services - part one: Dialysis and transnplantation. London: Author. Retrieved September 13, 2016, from http://www.dh.gov.uk/en/Publicationsandstatistics/Publications/PublicationsPolicyAn dGuidance/DH_4070359

Department of Health. (2005). The national service framework for renal services - part two: Chronic kidney disease, acute renal failure and end of life care. London: Author. Retrieved September 13, 2016, from http://www.dh.gov.uk/en/Publicationsandstatistics/Publications/PublicationsPolicyAn 


\section{dGuidance/DH_4101902}

Einollahi, B., Tavallaii, S., Bahaeloo-Horeh, S., Omranifard, V., Salehi-Rad, S., \& Khoddami-Vishteh, H. R. (2009). Marital relationship and its correlates in kidney recipients. Psychology, Health \& Medicine, 14(2), 162-169. doi: 10.1080/ 13548500802183567

Engel, G. L. (1980). The clinical application of the biopsychosocial model. American Journal of Psychiatry, 137(5), 535-544. Retrieved September 13, 2016, from http://ajp.psychiatryonline.org/

Gordon, E. J. (2001). Patients' decisions for treatment of end-stage renal disease and their implications for access to transplantation. Social Science \& Medicine, 53(8), 971-987. doi: 10.1016/s0277-9536(00)00397-x

Karaminia, R., Tavallaii, S. A., Lorgard-Dezfuli-Nejad, M., Moghani Lankarani, M., Hadavand Mirzaie, H., Einollahi, B., \& Firoozan, A. (2007). Anxiety and depression: a comparison between renal transplant recipients and hemodialysis patients. Transplantation Proceedings, 39(4), 1082-1084. doi:10.1016/j.transproceed.2007. 03.088

Kuntz, K. K., \& Bonfiglio, D. B. V. (2011). Psychological distress in patients presenting for initial renal transplant evaluation. Journal Of Clinical Psychology In Medical Settings, 18(3), 307-311. doi: 10.1007/s10880-011-9249-0

Luk, W. S. (2004). The HRQoL of renal transplant patients. Journal of Clinical Nursing, 13(2), 201-209. doi: 10.1046/j.1365-2702.2003.00867.x

Naiman, N., Baird, B. C., Isaacs, R. B., Koford, J. K., Habib, A. N., Wang, B. J., Barenbaum, L. L., \& Goldfarb-Rumyantzev, A. S. (2007). Role of pre-transplant marital status in renal transplant outcome. Clinical Transplantation, 21(1), 38-46. doi: 10.1111/j.13990012.2006.00575.x 
National Kidney Foundation. (2011). Managing your adult patients who have a kidney transplant. New York: Author. Retrieved September 13, 2016, from https://www.kidney.org/sites/default/files/02-504079_ABB_ManagingTransRecipBk_PC.pdf

NHS Blood and Transplant. (2015). Organ donation and transplantation: Activity report 2014/15. Watford: Author. Retrieved August 31, 2016, from http:// nhsbtmediaservices.blob.core.windows.net/organ-donationassets/pdfs/activity_report_2014_15.pdf

Noohi, S., Khaghani-Zadeh, M., Javadipour, M., Assari, S., Najafi, M., Ebrahiminia, M., \& Pourfarziani, V. (2007). Anxiety and depression are correlated with higher morbidity after kidney transplantation. Transplantation Proceedings, 39(4), 1074-1078. doi: 10.1016/j.transproceed.2007.04.002

Orr, A., Willis, S., Holmes, M., Britton, P., \& Orr, D. (2007). Living with a kidney transplant: a qualitative investigation of quality of life. Journal of Health Psychology, 12(4), 653-662. doi: 10.1177/1359105307078172

Pascazio, L., Nardone, I. B., Clarici, A., Enzmann, G., Grignetti, M., Panzetta, G. O., \& Vecchiet, C. (2010). Anxiety, depression and emotional profile in renal transplant recipients and healthy subjects: a comparative study. Transplantation Proceedings, 42(9), 3586-3590. doi: 10.1016/j.transproceed.2010.08.056

Pérez-San-Gregorio, M. A., Martín-Rodríguez, A., Galán-Rodríguez, A., \& Pérez-Bernal, J. (2005). Psychologic Stages in Renal Transplant. Transplantation Proceedings, 37(3), 1449-1452. doi: 10.1016/j.transproceed.2005.02.044

Sanner, M. A. (2003). Transplant recipients' conceptions of three key phenomena in transplantation: the organ donation, the organ donor, and the organ transplant. Clinical Transplantation, 17(4), 391-400. doi: 10.1034/j.1399-0012.2003.00065.x. 
Sanner, M. A., Lagging, E., \& Tibell, A. (2011). The kidney recipient's path to transplantation: a comparison between living and deceased kidney donor recipients in Stockholm, Sweden. Nephrology Dialysis Transplantation, 26(3), 1053-1057. doi: $10.1093 / \mathrm{ndt} / \mathrm{gfq} 462$

Schlebusch, L., Pillay, B. J., \& Louw, J. (1989). Depression and self-report disclosure after live related donor and cadaver renal transplants. South African Medical Journal, 75(10), 490-493. Retrieved September 13, 2016, from http://www.samj.org.za/index.php/samj

Smith, J. A., Flowers, P., \& Larkin, M. (2009). Interpretative phenomenological analysis: Theory, method and research. London: Sage.

Smith, J. A., \& Osborn, M. (2008). Interpretative phenomenological analysis. In J. A. Smith (Ed.), Qualitative psychology: A practical guide to research methods $\left(2^{\text {nd }} \mathrm{ed}.\right)$ (pp. 5380). London: Sage.

Spiers, J., \& Smith, J. A. (2015). Waiting for a kidney from a deceased donor: an interpretative phenomenological analysis. Psychology, Health and Medicine, 21 (7), 836-844. doi: 10.1080/13548506.2015.1112415

Spiers, J., Smith, J. A., \& Drage, M. (2015). A longitudinal interpretative phenomenological analysis of the process of kidney recipients' resolution of complex ambiguities within relationships with their living donors. Journal of Health Psychology, ISSN 13591053. (In Press). doi: $10.1177 / 1359105315581070$

Troen, A. M., Scott, T. M., D’Anci, K. E., Moorthy, D., Dobson, B., Rogers, G., \& Rosenberg, I. H. (2012). Cognitive Dysfunction and Depression in Adult Kidney Transplant Recipients: Baseline Findings from the FAVORIT Ancillary Cognitive Trial (FACT). Journal of Renal Nutrition, 22(2), 268-276. doi: 10.1053/j.jrn.2011.07.009 
Wainwright, S. P., Fallon, M., \& Gould, D. (1999). Psychosocial recovery from adult kidney transplantation: a literature review. Journal of Clinical Nursing, 8(3), 233-245. doi: 10.1046/j.1365-2702.1999.00220.x

Wiederhold, D., Langer, G., \& Landenberger, M. (2011). Ambivalent lived experiences and instruction need of patients in the early period after kidney transplantation: A phenomenological study. Nephrology Nursing Journal, 38(5), 417-424. Retrieved September 13, 2016, from http://www.ovid.com/site/catalog/Journal/1861.jsp

Wood, E. (2014). Patient-to-patient peer support in renal care: what, why and how? Journal of Renal Nursing, 6(5), 239-243. Retrieved September 13, 2016, from http://www.magonlinelibrary.com/toc/jorn/current 
Table 1

Demographic Features of Participants

\begin{tabular}{|c|c|c|c|c|}
\hline Pseudonym & Age & $\begin{array}{l}\text { Time since transplant } \\
\text { (in months) }\end{array}$ & $\begin{array}{l}\text { Cohabiting with } \\
\text { Spouse/ Partner? }\end{array}$ & $\begin{array}{l}\text { Employment } \\
\text { Status }\end{array}$ \\
\hline John & 26 & 11 & Yes & $\begin{array}{l}\text { Employed } \\
\text { (part-time) }\end{array}$ \\
\hline David & 33 & 13.5 & No & Unemployed \\
\hline Mary & 35 & 7 & No & Employed \\
\hline Matthew & 52 & 9 & Yes & Employed \\
\hline Alan & 56 & 21 & Yes & Retired \\
\hline Rob & 68 & 17 & Yes & Retired \\
\hline
\end{tabular}

Word Count: 8,188 (including title, abstract, keywords, references and table) 